EGU2020-941, updated on 25 Mar 2021

https://doi.org/10.5194/egusphere-egu2020-941

EGU General Assembly 2020

(c) Author(s) 2021. This work is distributed under

the Creative Commons Attribution 4.0 License.

\title{
Beach-foredune ridges as proxies for climate-induced wave direction changes in South Atlantic during Late Holocene
}

\author{
Ana Paula Da Silva ${ }^{1,2}$, Antonio Henrique da Fontoura Klein ${ }^{1}$, Antonio Fernando Harter Fetter \\ Filho ${ }^{1}$, Christopher Hein ${ }^{3}$, Fernando Mendez ${ }^{4}$, Micael Broggio ${ }^{1}$, and Charline Dalinghaus ${ }^{1}$ \\ ${ }^{1}$ Graduate Program in Oceanography, Federal University of Santa Catarina, Brazil \\ ${ }^{2}$ Griffith University, Griffith Centre for Coastal Management, Gold Coast, Australia (ana.dasilva@griffithuni.edu.au) \\ ${ }^{3}$ Virginia Institute of Marine Science, USA \\ ${ }^{4}$ Department of Sciences and Techniques in Water and Environment, Cantabria University, Spain
}

Variability in global wave climate has been observed to occur in response to climate changes influencing the wave-generating zones. This highlights the need for an improved understanding of long-term wave-climate cycles, considering the multi-decadal variability of the atmospheric patterns and large-scale climate drivers. In this study, a novel use of the morphology of former shorelines preserved in beach-foredune ridges was applied to reconstruct changes in predominant wave directions in the Subtropical South Atlantic during the Late Holocene. A $3 \mathrm{~km}$ wide semi-continuous sequence of beach-foredune ridges preserved within the Pinheira Strandplain (Santa Catarina State, Brazil) was mapped in order to extract the orientation of the former shorelines and derive a 3000-year record of inferred mean wave direction. The mean wave direction series was compared to 1000 years of decadal means of mid-latitude mean sea-level pressure gradients (â\&\#136;\&\#134;MSLP) and zonal westerly wind velocities estimated from the CESM1-CAM5 "Last Millennium Ensemble (LME)", and to 2000 years of air-surface temperature anomalies for Southern Hemisphere. Results showed that multi-centennial cycles of oscillation in predominant wave direction occurred in accordance with stronger (weaker) South Atlantic midlatitude mean sea-level pressure and zonal westerlies winds, favouring wave generation zones in higher (lower) latitudes and consequent southerly (easterly) wave climate dominance. It was identified the Southern Annular Mode as the main climate driver responsible for these changes, responding for $43 \%$ of the variance in the Subtropical South Atlantic atmospheric patterns in the last 1000 years. Long-term variations in interhemispheric air-surface temperature offsets, coincident with oscillations in wave direction, may have influenced wave-generation patterns similarly to the seasonal behaviour observed over recent decades. Periods of relatively warmer Southern Hemisphere (SH) as compared with Northern Hemisphere (NH) (e.g., during 400-800 CE and the Little Ice Age) favours the predominance of easterly wave energy flux along the eastern South American coast, whereas periods with equivalent NH-SH temperature anomalies (e.g., Medieval Warm Period) or with colder relative SH (last 150 years) support an increase in the influence of the southerly wave energy flux over the South Atlantic. These results provide a novel geomorphic proxy for paleoenvironmental reconstructions and present new insights into the role of multi-decadal to multi-centennial climate variability on controlling coastal ocean wave climate. 
